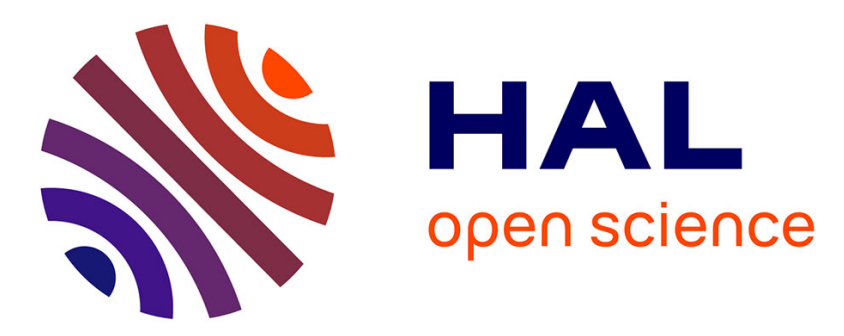

\title{
A New Approach to Determine Autogenous Shrinkage of Mortar at Early Age Considering Temperature History
}

Ahmed Loukili, David Chopin, Abdelhafid Khelidj, Jean-Yves Le Touzo

\section{To cite this version:}

Ahmed Loukili, David Chopin, Abdelhafid Khelidj, Jean-Yves Le Touzo. A New Approach to Determine Autogenous Shrinkage of Mortar at Early Age Considering Temperature History. Cement and Concrete Research, 2000, 30 (6), pp.915-922. 10.1016/S0008-8846(00)00241-6 . hal-01004907

\section{HAL Id: hal-01004907 https://hal.science/hal-01004907}

Submitted on 2 Feb 2017

HAL is a multi-disciplinary open access archive for the deposit and dissemination of scientific research documents, whether they are published or not. The documents may come from teaching and research institutions in France or abroad, or from public or private research centers.
L'archive ouverte pluridisciplinaire HAL, est destinée au dépôt et à la diffusion de documents scientifiques de niveau recherche, publiés ou non, émanant des établissements d'enseignement et de recherche français ou étrangers, des laboratoires publics ou privés.

\section{(c)(1)}

Distributed under a Creative Commons Attribution| 4.0 International License 


\title{
A new approach to determine autogenous shrinkage of mortar at an early age considering temperature history
}

\author{
Ahmed Loukili $^{\mathrm{a}, *}$, David Chopin ${ }^{\mathrm{a}}$, Abdelhafid Khelidj ${ }^{\mathrm{b}}$, Jean-Yves Le Touzo ${ }^{\mathrm{a}}$ \\ ${ }^{a}$ Laboratoire Génie Civil de Nantes St-Nazaire, Ecole Centrale de Nantes, BP 92101, 44321 Nantes Cedex, France \\ ${ }^{\mathrm{b}}$ IUT, BP 420, 44606 Saint-Nazaire, France
}

\begin{abstract}
Shrinkage, settlement, and thermal deformations of concrete start to develop as soon as the casting is finished. The majority of standard tests currently used to measure free deformations are carried out on hardened concrete. Therefore, the prediction of thermal and other stresses at an early age cannot be determined. This article describes the design and the operation of an experimental device used for measuring the volume change of mortar in relation to the real temperature history. Measurements are carried out on a mortar having a water/cement (W/C) ratio of 0.35 and started approximately $20 \mathrm{~min}$ after the addition of water in the mixture up to $24 \mathrm{~h}$ of hydration. The measured deformation includes autogenous shrinkage and thermal expansion or contraction caused by the temperature changes induced by the heat of cement hydration. An experimental method is proposed to uncouple these deformations. The investigations show that the autogenous shrinkage amplitude is strongly affected by the temperature history of mortar. Therefore, for a good estimate of the shrinkage amplitudes of cement based material, temperature must be taken into account in testing.
\end{abstract}

Keywords: Fresh mortar; Early age; Temperature; Autogenous shrinkage; Thermal dilation coefficient

\section{Introduction}

For practical use of cement-based materials, good knowledge of their mechanical behavior is necessary. Shrinkage, among others, is a very important property for the good working of a structure since it very often generates either early age cracking (thermal shrinkage and autogenous shrinkage) or late cracking (drying shrinkage). The correct knowledge of the phenomena governing the free deformations of the concrete and the evaluation of their real amplitudes make it possible to avoid cracking and consequently, to guarantee a better durability of the structures.

The volume change involved by the hydration reaction of cement starts from the beginning of the making concrete. Usually, the measurement of shrinkage deformations is carried out on hardened concrete. With this test method, the deformations of the freshly mixed concrete are completely ignored and may result in the statement of inaccurate laws of behavior.
Among the methods available to assess measurement of volume change of concrete at early age, we have the measurement of buoyancy variations using Archimedes' principle [1,2]. This method consists in introducing fresh cementing material into a flexible latex mold (prophylactic) and in immersing it in a volume of water at constant temperature in order to carry out the hydrostatic weighing of the sample. Taking good care to comply with the precautions listed by Justnes et al. [1], this technique allows for a satisfactory evaluation of the variations in volume of material under isothermal conditions. On the other hand, this method does not take into account the evolution of the thermal conditions within the material. Indeed, shrinkage can be activated by a variation in temperature due to the exothermal effect of the reaction of hydration, and possibly compensated by the thermal dilation involved by the increase in temperature. Moreover, the thermal gradient, which is considerable between the periphery and the core of a concrete structure, involves a gradient of stresses and influences the total shrinkage. The study first consists in developing an experimental tool, which allows us to measure the shrinkage at an early age by considering the temperature history undergone by the cement-based materi- 
Table 1

Mix composition

\begin{tabular}{llll}
\hline Cement $\left(\mathrm{kg} / \mathrm{m}^{3}\right)$ & Aggregates $\left(\mathrm{kg} / \mathrm{m}^{3}\right)$ & Water $\left(\mathrm{kg} / \mathrm{m}^{3}\right)$ & W/C \\
\hline 700 & 1216 & 245 & 0.35
\end{tabular}

al. We then present an experimental method that makes a separation of autogenous shrinkage and thermal deformation possible.

The terms used in the present paper are defined as follows:

\section{Total deformation}

measured deformation of the mortar caused by cement reactions including autogenous and thermal deformations.

Autogenous shrinkage

is the difference between total deformation defined above and thermal deformation, which is calculated from the measured Thermal Dilation Coefficient (TDC).

\section{Materials and experimental methods}

\subsection{Materials}

The mix composition of the studied mortar is shown in Table 1. A Portland cement (CPA CEM I 52.5 R) containing $66.9 \% \mathrm{C}_{3} \mathrm{~S}, 19.2 \% \mathrm{C}_{2} \mathrm{~S}, 4.35 \% \mathrm{C}_{3} \mathrm{~A}$ and $1 \% \mathrm{C}_{4} \mathrm{AF}$ was used. Water/cement $(\mathrm{W} / \mathrm{C})$ ratio was selected at 0.35 in order to avoid bleeding [1]. The aggregate was quartzite sand with a maximum nominal size of $4 \mathrm{~mm}$.

Cement and sand were mixed in a 5-1 laboratory mixer for $1 \mathrm{~min}$ before the addition of water and a further mixing period of $3 \mathrm{~min}$ to ensure a homogeneous mix.

\subsection{Experimental methods}

Measurements of external volume change of mortar caused by cement reactions were taken by hydrostatic weighing. The principle of this method consists in measuring the buoyancy variations of a sample at a very early age (Fig. 1). The studied mortar is introduced into a prophylactic immediately after casting. The prophylactic is turned inside out so that the lubricant is now inside it. This reduces the friction between mortar and the membrane. The prophylactic is then filled up with about 300 to $400 \mathrm{~g}$ of material [1]. The latex mold is then closed using a thin stainless steel wire. The greatest care is exercised to evacuate air. The presence of air in the mold is indeed undesirable because the contraction pores, which form during the hydration reaction, suck in this air and cause a reduction in the volume of the latex envelope that can wrongly be interpreted as shrinkage. The excess latex is then cut and the sample container is cleaned and weighed. Then, the sample is placed in the nacelle, which is hung on a balance, and immersed immediately in the water bath at $20^{\circ} \mathrm{C}$ (Fig. 1). The external volume change of mortar results in the modification of buoyancy force and varies the mass read on the balance. The accuracy of the balance was about $0.01 \mathrm{~g}$. It can be noticed that the choice of the prophylactic guarantees a good seal with respect to the surrounding medium. Moreover, the elasticity of latex membrane allows free deformations of mortar.

We then make the $110 \times 220 \mathrm{~mm}$ cylindrical specimen, which is introduced in a quasi-adiabatic enclosure immediately after casting (Fig. 2). It can be noticed that all mortar specimens come from a single batch. Two thermocouples are placed in the specimen at $1 \mathrm{~cm}$ (point A) and $5 \mathrm{~cm}$ (point

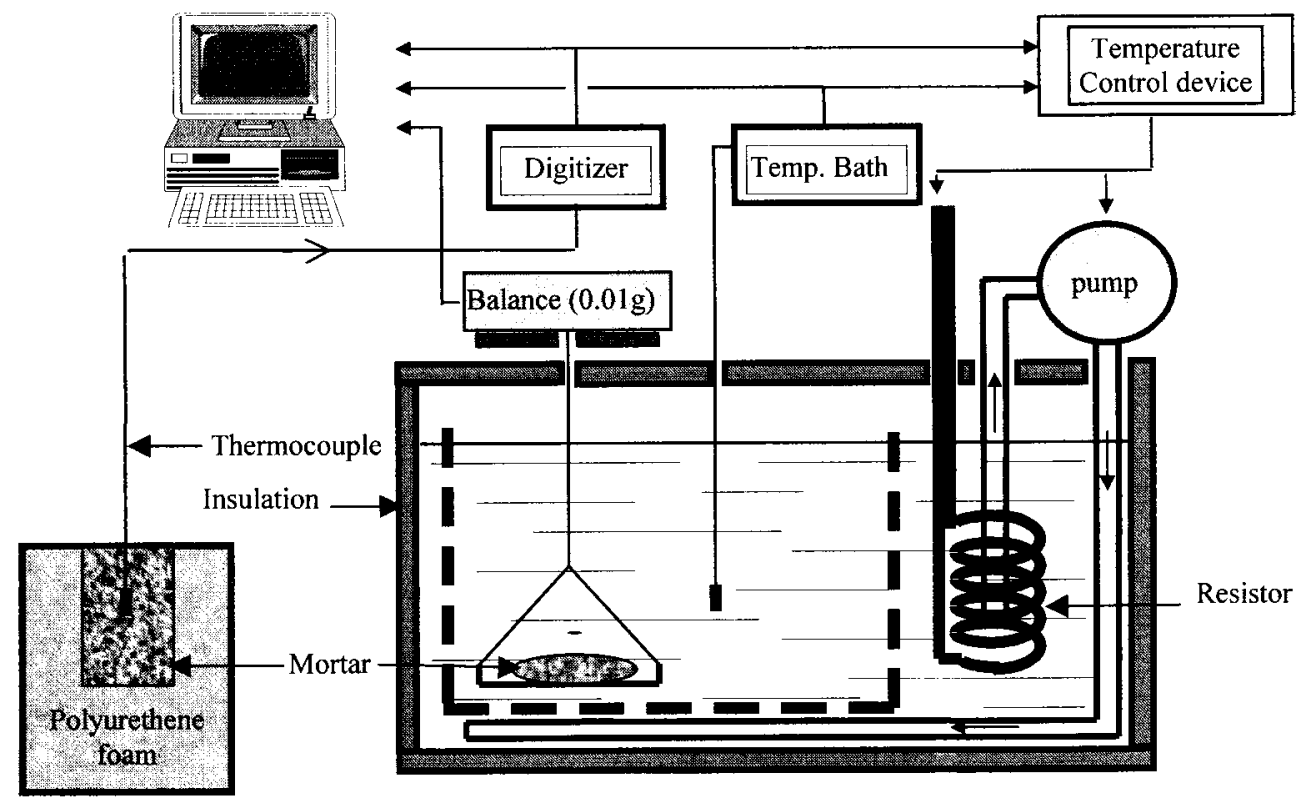

Fig. 1. Schematic drawing of the experimental system. 


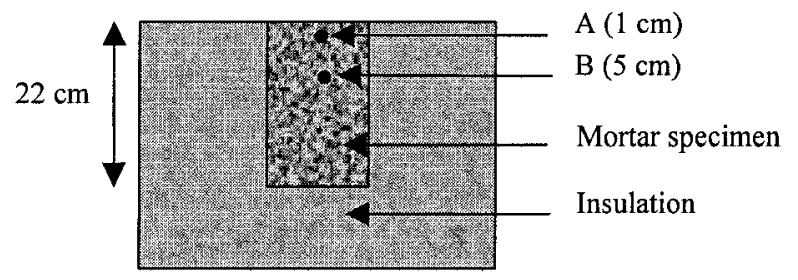

Fig. 2. Sample giving the temperature history.

B) below the surface, respectively so as to obtain two different temperature histories.

The shape and the position of this sample make a representation of the conditions existing in a $44-\mathrm{cm}$ thick floor possible (Fig. 2).

To be able to measure the deformations under various thermal conditions, it was necessary to develop a system which allows to apply to the bath the temperature recorded into the mortar. This system works according to the principle of comparison of the two temperatures thanks to a regulator (Fig. 1). When the bath temperature is lower than that of the mortar specimen, the regulator starts a resistor and a water pump. The power of the resistor makes it possible to obtain a fast increase in the temperature and thus accurate control. The role of the water pump is to homogenize the temperature of the water bath. The experimental device was set up in a room at $20^{\circ} \mathrm{C}$ and $50 \%$ relative humidity. Temperature of the bath, temperature of the sample, and the mass measured by the balance are logged continuously on the computer every $10 \mathrm{~min}$ during $24 \mathrm{~h}$. The temperature histories are measured at 1 and $5 \mathrm{~cm}$ below the surface for two reasons. First, the temperatures reached in the core of the cylindrical specimen are too high so that measurements remain reliable in the bath. Moreover, it makes it possible to show that the temperature histories of two very close points are eventually very different.

It is worth noting that the prophylactic used in this study cannot be used to measure the shrinkage of concrete (the aggregates would be likely to puncture the rubber bag). So, the tests are carried out on a mortar in order to obtain a behavior closer to that of the concrete than that of the cement paste.

\subsection{Correction of the obtained results}

During an isothermal test at $20^{\circ} \mathrm{C}$, the value read on the balance gives the volume change of the sample directly (specific gravity of water is constant). In this study, the temperature of water varies significantly (from $20^{\circ} \mathrm{C}$ to $65^{\circ} \mathrm{C}$ ) leading to a variation of the water density. Carrying out a correction of this value to determine the volume change of mortar is then necessary.

The formula giving the density of water $\rho_{\mathrm{e}}(T)$ between $17^{\circ} \mathrm{C}$ and $100^{\circ} \mathrm{C}$ [3] is expressed by Eq. (1):

$$
\rho_{\mathrm{w}}(T)=1-\frac{(T-3.982)^{2}}{466,700} \frac{T+273}{T+67} \frac{350-T}{365-T}
$$

It then becomes a question of writing the balance of the system of forces acting on the sample. By considering an isotropic behavior of material, the linear deformation is given by one-third of the volumetric deformation. The linear deformation is then obtained by Eq. (2) resulting from the calculation detailed in [4]:

$\varepsilon=\frac{1}{3}\left[\left(\frac{\rho_{\mathrm{iw}}}{\rho_{\mathrm{w}}(T)}-1\right)-\frac{M_{\mathrm{r}}}{V_{\mathrm{i}} \rho_{\mathrm{w}}(T)}\right]$

where $T$ : temperature of bath $\left({ }^{\circ} \mathrm{C}\right) ; \rho_{\text {iw }}$ : initial density of

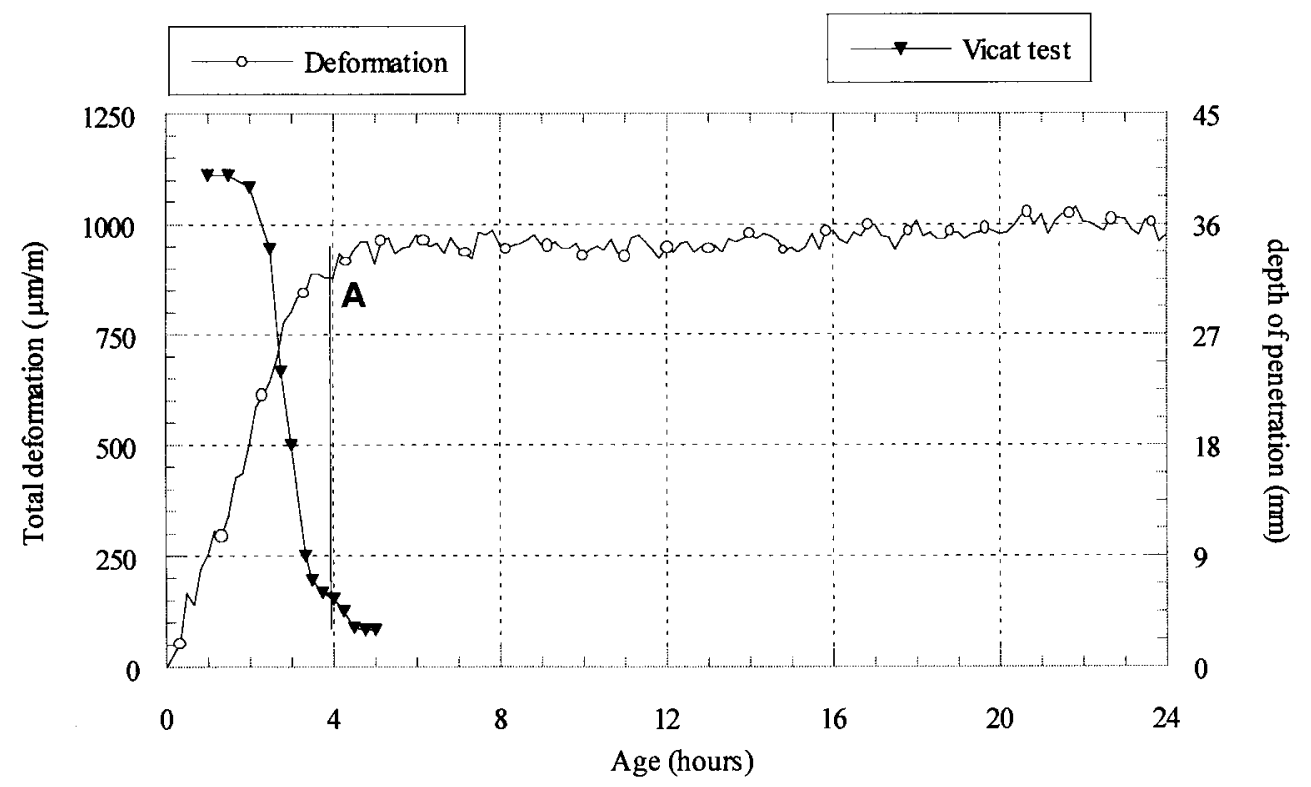

Fig. 3. Total shrinkage and Vicat test at $20^{\circ} \mathrm{C}$. 


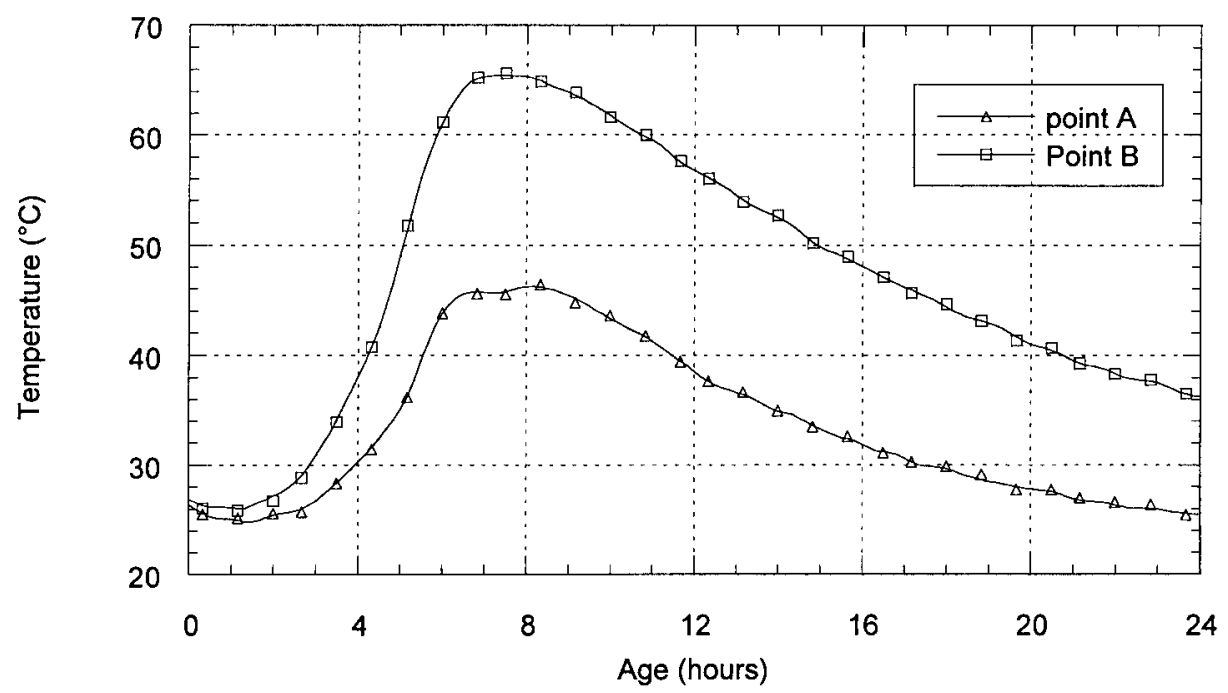

Fig. 4. Temperature histories in mortar specimen.

water $\left(\mathrm{g} / \mathrm{cm}^{3}\right) ; V_{\mathrm{i}}$ : initial volume of the sample $\left(\mathrm{cm}^{3}\right)$; $\rho_{\mathrm{w}}(T)$ : density of water as function of temperature $\left(\mathrm{g} / \mathrm{cm}^{3}\right)$; $\varepsilon$ : linear deformation of mortar $(\mu \mathrm{m} / \mathrm{m}) ; M_{\mathrm{r}}$ : mass read on the balance $(\mathrm{g})$.

\section{Results and discussions}

Three series of tests have been carried out. The first series consists in measuring the volume change of the sample at a constant temperature $\left(20^{\circ} \mathrm{C}\right)$. This series allows a validation of the experimental device while referring to previous studies. It also allows us to obtain a reference curve for the analysis of the results in quasi-adiabatic conditions. The two other series of tests consist in applying to the sample the temperature histories measured at 1 and $5 \mathrm{~cm}$ below the surface of a $110 \times 220$-mm mortar specimen.

\subsection{Reference test at $20^{\circ} \mathrm{C}$}

For this test, the sample is placed in the water bath at a temperature of $20 \pm 0.5^{\circ} \mathrm{C}$. Simultaneously, Vicat test apparatus is used to determine the initial and final set of the mortar.

The results of this test (Fig. 3) show traditional kinetics of the shrinkage also observed by other authors [2]. A

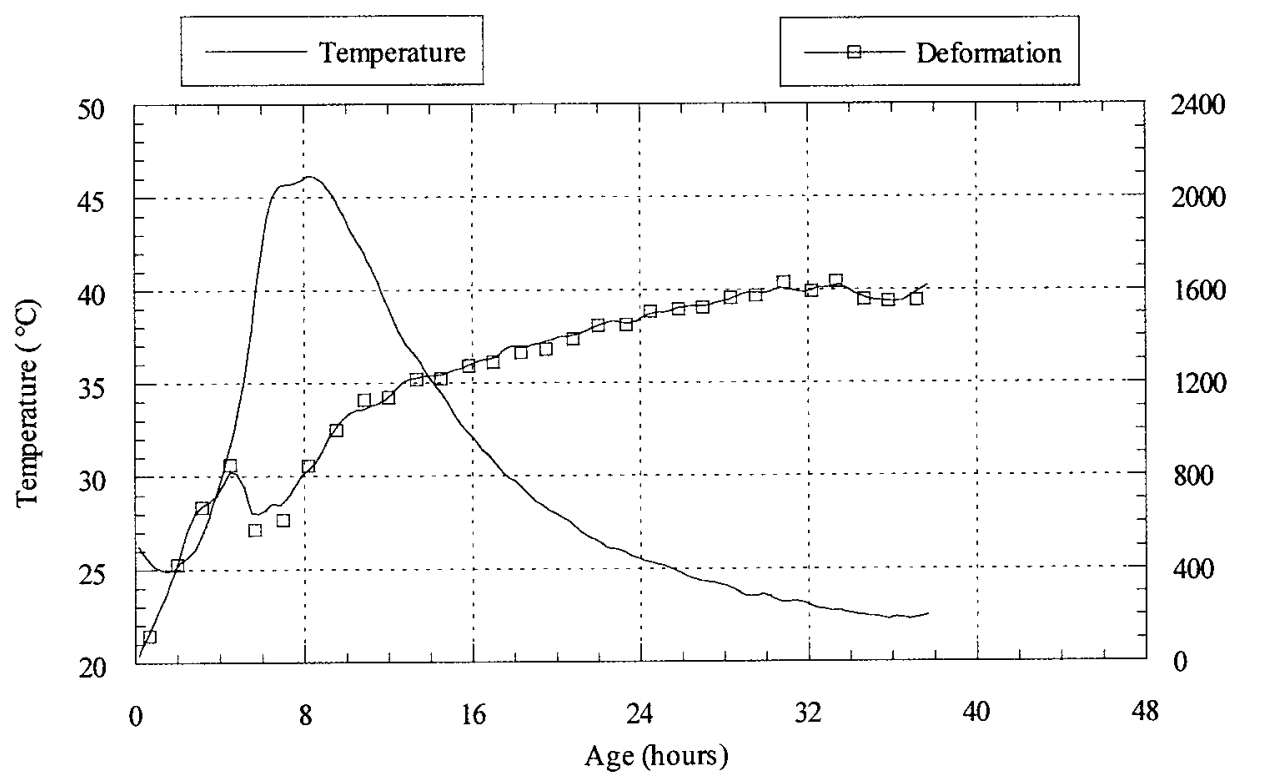

Fig. 5. Total deformation of the sample with $46^{\circ} \mathrm{C}$ maximum (point A). 


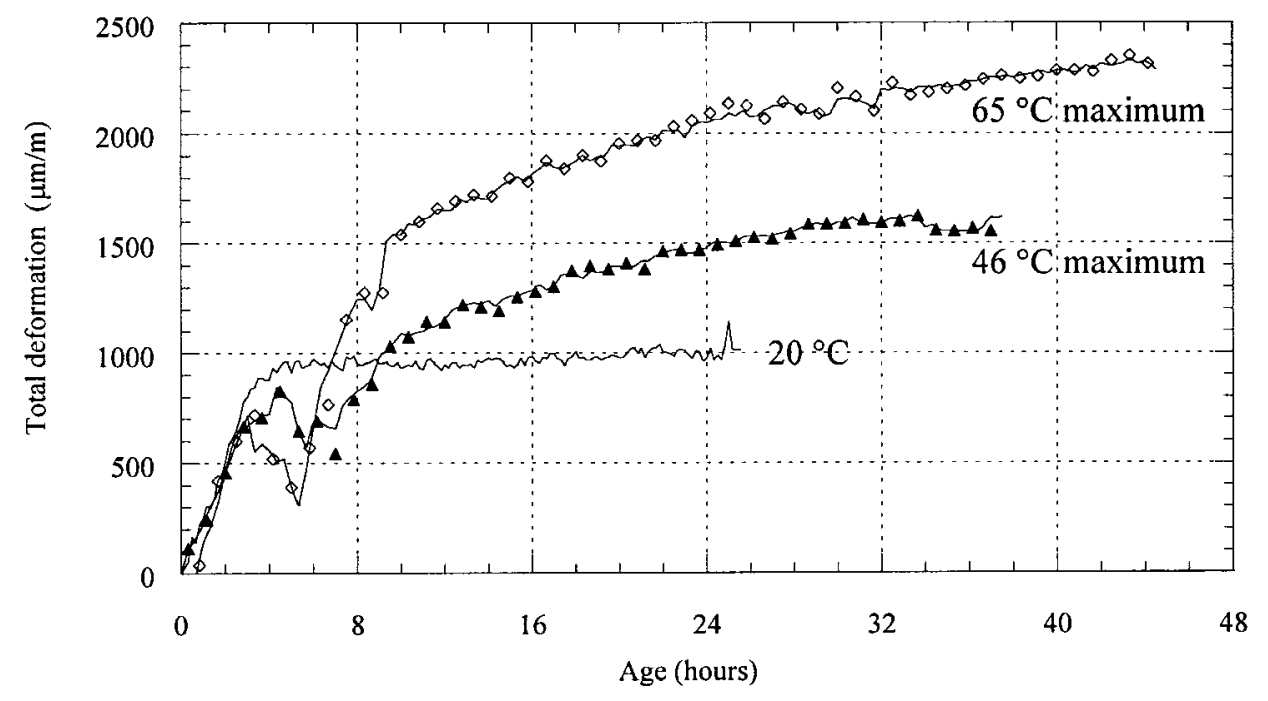

Fig. 6. Comparison of the total deformations for different temperature histories.

significant amount of shrinkage is observed during the first $4 \mathrm{~h}$. Then, the shrinkage curve flattens (point A) and then the deformation evolves slowly.

It is significant to note that point A corresponds to the end of setting period (about $240 \mathrm{~min}$ ) characterized by a quasi-constant depth of penetration of the needle into the mortar. At this time, the skeleton is formed and is stiff sufficiently to restrain deformation caused by hydration reactions.

\subsection{Measurement of external volume change in quasi adiabatic conditions}

Fig. 4 show the temperature evolution into the cylindrical specimen. The maximum temperature ob- served was $65^{\circ} \mathrm{C}$ at point $\mathrm{B}$ and $46^{\circ} \mathrm{C}$ at point $\mathrm{A}$ about $7 \mathrm{~h}$ after placing the mortar. The maximum temperature differential between the two points was about $20^{\circ} \mathrm{C}$. It is important to note that the critical temperature difference to avoid cracking during cooling is $20^{\circ} \mathrm{C}$ [5].

Effects of temperature history on total deformation are shown in Figs. 5 and 6. It appears that the kinetics and amplitude of these curves are very different from those obtained at $20^{\circ} \mathrm{C}$. Indeed, it can be observed a swelling of the sample during the period when the increase in temperature is most significant ( 5 to $7 \mathrm{~h}$ ).

This swelling occurs earlier and is all the more marked since the temperature reached is high (Fig. 6). This leads to a phenomenon, which is more important for points

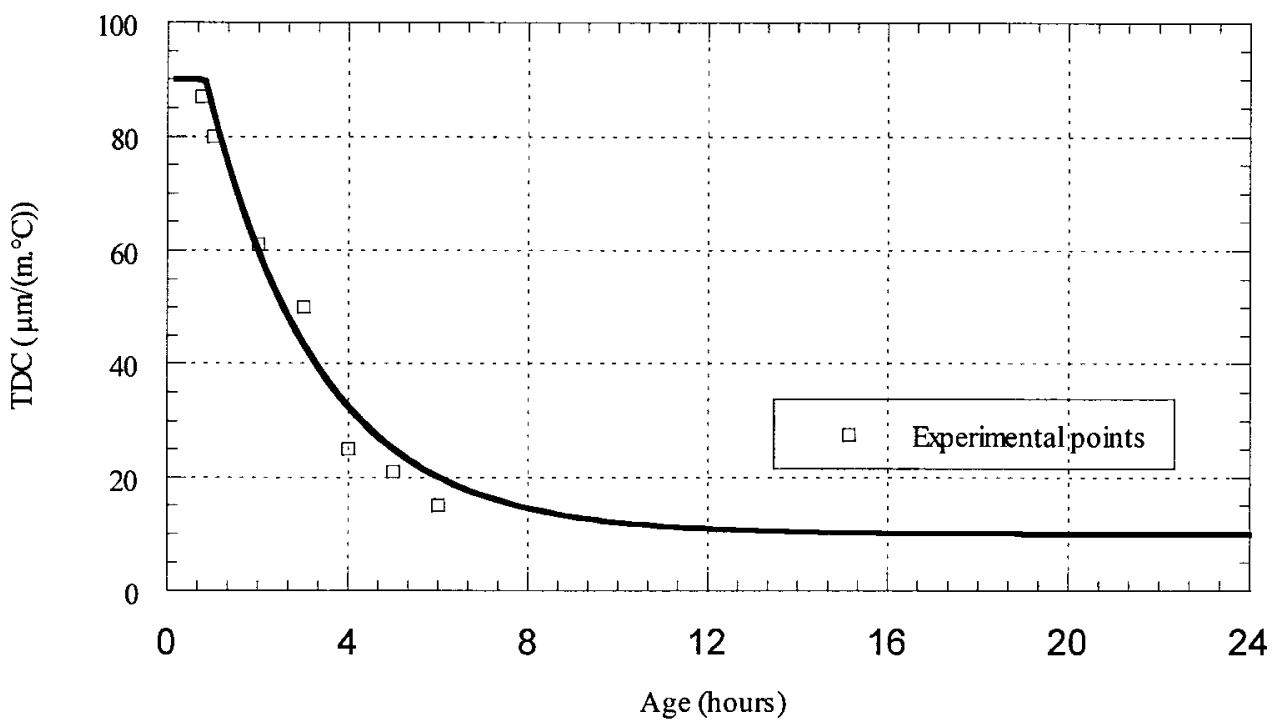

Fig. 7. Evolution of TDC. 
Table 2

Experimental measurement of TDC

\begin{tabular}{lcrrrrrr}
\hline Age $(\mathrm{h})$ & 0.75 & 1 & 2 & 3 & 4 & 5 & 6 \\
TDC $\left(\mu \mathrm{m} / \mathrm{m} /{ }^{\circ} \mathrm{C}\right)$ & 87 & 80 & 61 & 50 & 25 & 21 & 15 \\
\hline
\end{tabular}

located near the core of the structure where the temperature reaches $60^{\circ} \mathrm{C}$.

The total measured deformation includes autogenous shrinkage and thermal deformation which depends on the TDC of mortar. For better analysis of these curves, it would be very instructive to separate the thermal deformation from the autogenous shrinkage. Following this work, we propose a new experimental method to determine TDC based on hydrostatic weighing method.

\subsection{TDC measurements}

The sample studied, placed under variable conditions of temperature, undergoes volumetric variations of thermal origin which are difficult to evaluate since the microstructure of material varies with time. Measuring this coefficient by using the hydrostatic weighing device brought under control in temperature is possible. Indeed, the thermal dilation of a sample can be caused by an increase in the temperature of the bath. If this rise in temperature is sufficiently fast, the measured deformation will be only of thermal origin.

The TDC is measured immediately after batching every hour during $6 \mathrm{~h}$. Tests are carried out on six different samples. The measurement of TDC is carried out by the method of spontaneous heating of the sample. For each measurement, the temperature of the bath is initially about $20^{\circ} \mathrm{C}$ and increased $10^{\circ} \mathrm{C}$ during $10 \mathrm{~min}$. The results of these experiments are reported in Table 2 and plotted in Fig. 7.

Our own measurement device is not sensitive enough to consider the low TDC values reliable. Therefore, the continuation of the TDC curve after $6 \mathrm{~h}$ is extrapolated from the experimental results and from the kinetics of the curves found in Ref. [5] according to Eq. (3):

$\operatorname{TDC}(t)=77 * \mathrm{e}^{\frac{0.75}{2.5}}+10$

where, TDC $\left(\mu \mathrm{m} / \mathrm{m} /{ }^{\circ} \mathrm{C}\right) ; t$ : age of mortar (h).

Fig. 7 shows that TDC is not constant at an early age of mortar. At $1 \mathrm{~h}$, the TDC reaches $90 \mu \mathrm{m} / \mathrm{m} /{ }^{\circ} \mathrm{C}$, then it decreases very quickly and reaches $15 \mu \mathrm{m} / \mathrm{m} /{ }^{\circ} \mathrm{C}$ after $6 \mathrm{~h}$. These results are in agreement with the findings of Laplante [6] for ordinary concrete. The amplitude, however, is different since the compositions are themselves different. It is significant to note that the rapid decrease of TDC (during the first $5 \mathrm{~h}$ ) corresponds to the period when the material passes from a liquid state to a hardened state. Laplante [6] suggests an explanation for the particular kinetics of TDC based on theory of percolation [7]. The high TDC value observed at an early age corresponds to the time when the water phase dominates. When the mortar starts to stiffen, the TDC may not be influenced by the volume changes due to the free water movements but may be essentially influenced by the characteristics of porous structure.

\subsection{Proposition of a method to separate thermal and autogenous deformations}

To be able to determine autogenous shrinkage in a satisfactory manner, it is necessary to calculate the deformation of thermal origin using the TDC values. For each

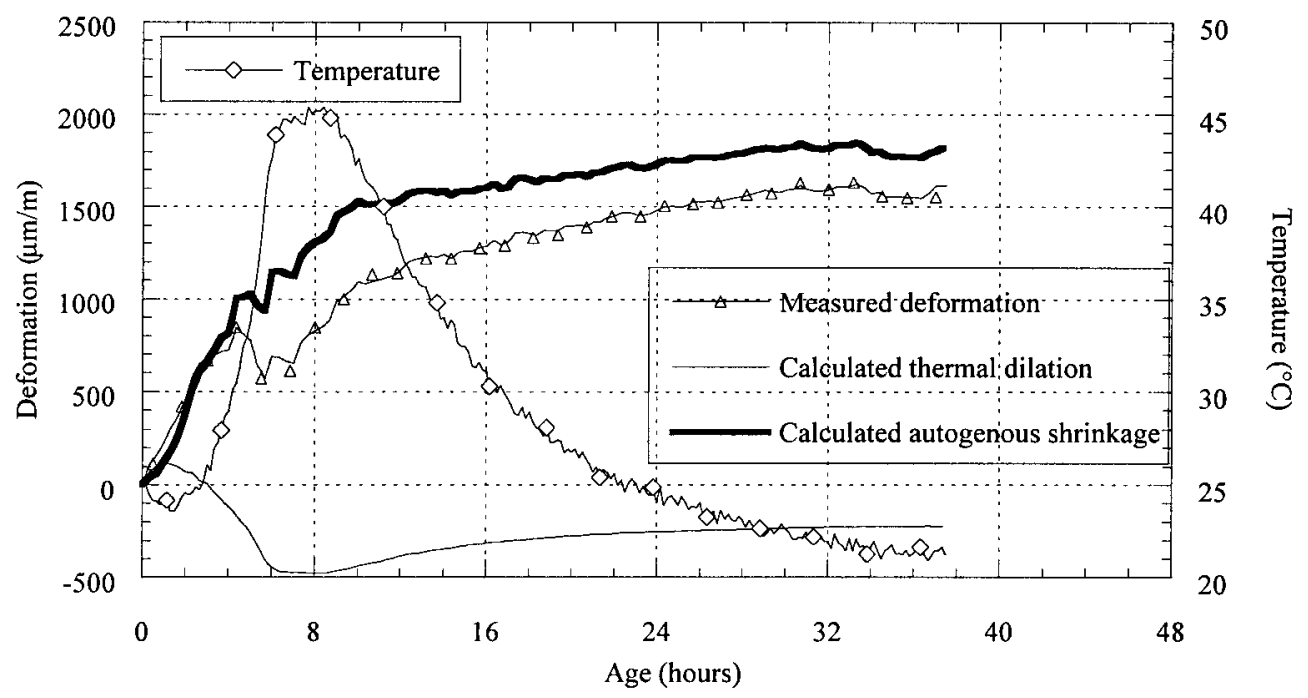

Fig. 8. Separation of thermal and autogenous deformations for $2546^{\circ} \mathrm{C}$ temperature history. 


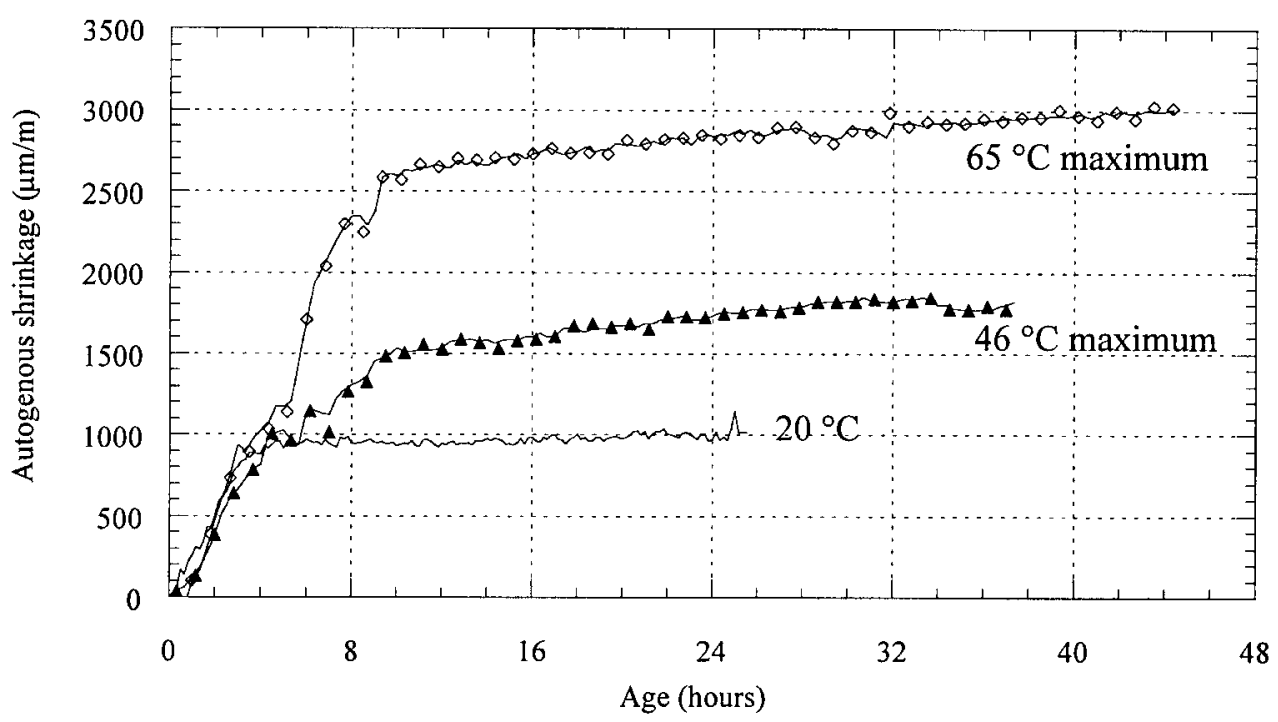

Fig. 9. Comparison of autogenous shrinkage for the different thermal conditions.

new measurement, the thermal strain is calculated compared to the previous measurement (step-by-step) according to Eq. (4):

$$
\begin{aligned}
\varepsilon(n)= & \varepsilon(n-1) \\
& +\left[[T(n)-T(n-1)] \frac{\operatorname{TDC}(n)+\operatorname{TDC}(n-1)}{2}\right]
\end{aligned}
$$

where $T(n)$ is the temperature, $\operatorname{TDC}(n)$ the thermal dilation coefficient and $\varepsilon(n)$ the thermal deformation at the $n$ time step.

By subtracting the thermal deformation from the measured total deformation, the true self-desiccation shrinkage is obtained. The principle of this calculation is illustrated in Fig. 8 for the temperature history with $46^{\circ} \mathrm{C}$ maximum.

Fig. 8 shows that the material undergoes a significant thermal dilation during temperature rise period which partly compensates for the shrinkage. Then, the thermal dilation is followed by a return of dilation (thermal shrinkage) during the cooling stage, which occurs on hardened material. Therefore, thermal deformation is added to the autogenous shrinkage instead of compensating for it as what happened during the first phase.

Fig. 9 presents the calculated autogenous shrinkage for the three temperature histories using the TDC values given in Fig. 7. The main observation is that the autogenous shrinkage amplitude of sample with $65^{\circ} \mathrm{C}$ maximum (point A) is about three times higher than that observed in the quasi-isothermal test at $20^{\circ} \mathrm{C}$. It can be concluded that the amplitude of autogenous shrinkage is strongly dependent on the temperature history the material undergoes. Therefore, for a good estimate of the shrinkage amplitudes of a cement-based material, temperature must be taken into account in testing. These results could be of great importance for practical applications; in particular, for highperformance concrete, which has a significant autogenous shrinkage at an early age.

\section{Conclusions}

The main conclusions that can be drawn from this experimental investigation are the following:

1. Design and validation of an experimental process allows us to determine total deformation of mortar at an early age under real conditions of construction. Indeed, the tests can determine the volume change vs. the temperatures recorded in mortar in real time.

2. An experimental method is proposed to determine the Thermal Dilation Coefficient of cement-based materials. This made it possible to separate thermal and autogenous deformations.

3. The amplitude of autogenous shrinkage is strongly affected by the temperature history of the mortar.

4. Not to take into account the temperature history of material in a shrinkage test at early age leads, in our opinion, to a false estimate of autogenous shrinkage amplitude.

\section{References}

[1] H. Justnes, B. Reyniers, D. Van Loo, E.J. Sellevold, An evaluation of methods for measuring chemical shrinkage of cementitious paste Nord Concr Res 14 (1994) 4561. 
[2] H. Justnes, A. Van Gemert, A. Verboven, E.J. Sellevold, Total and external chemical shrinkage of low W/C-ratio cement pastes Adv Cem Res 8 (31) (1996) 121126.

[3] M. Duriez, J. Arrambide, Nouveau Traité de Matériaux de Construction, Dunod, Paris, 1961.

[4] D. Chopin, Développement d'un dispositif de mesure du retrait des mortiers au jeune age, DEA, Ecole Centrale de Nantes, 1998.
[5] A.M. Neville, Properties of Concrete, 3rd edn. Pitman, London, 1981.

[6] P. Laplante, Propriétés Mécaniques Des Bétons Durcissants: Analyse Comparée des Bétons Classiques et a Tres Hautes Performances, PhD Thesis, Ecole Nationale des Ponts et Chaussées, Paris, 1993.

[7] P. Acker, Comportement Mécanique du Béton: Apports de l'Approche Physico-Chimique, Research Report LPC, No. 152, 1988. 